\title{
Shedding light on the subject: introduction to illumination engineering and design for multidiscipline engineering students
}

\section{Ram Ronen, R. Frank Smith}

Ram S. Ronen, R. Frank Smith, "Shedding light on the subject: introduction to illumination engineering and design for multidiscipline engineering students," Proc. SPIE 2525, 1995 International Conference on Education in Optics, (13 October 1995); doi: 10.1117/12.224042

SPIE Event: SPIE's 1995 International Symposium on Optical Science, Engineering, and Instrumentation, 1995, San Diego, CA, United States 


\title{
Shedding Light on the Subject: \\ Introduction to Illumination Engineering and Design for Multi-Discipline Engineering Students
}

\author{
Ram S. Ronen and R. Frank Smith \\ College of Engineering, Electrical and Computer Engineering Department \\ California State Polytechnic University, Pomona, California
}

\begin{abstract}
Educating engineers and architects in Illumination Engineering and related subjects has become a very important field and a very satisfying and rewarding one. Main reasons include the need to significantly conserve lighting energy and meet government regulations while supplying appropriate light levels and achieving aesthetical requirements. The proliferation of new lamps, luminaires and lighting controllers many of which are "energy savers" also helps a trend to seek help from lighting engineers when designing new commercial and residential buildings. That trend is believed to continue and grow as benefits become attractive and new government conservation regulations take effect. To make things even better one notices that Engineering and Science students in most disciplines make excellent candidates for Illumination Engineers because of their background and teaching them can move ahead at a brisk pace and be a rewarding experience nevertheless.
\end{abstract}

In the past two years, Cal Poly Pomona College of Engineering has been the beneficiary of a DOE/California grant. Its purpose was to precipitate and oversee light curricula in various California community colleges and also develop and launch an Illumination Engineering minor at Cal Poly University. Both objectives have successfully been met. Numerous community colleges throughout California developed and are offering a sequence of six lighting courses leading to a certificate; the first graduating class is now coming out of both Cypress and Consumnes Community Colleges. At Cal Poly University a four course/laboratory sequence leading to a minor in Illumination Engineering (ILE) is now offered to upper division students in the College of Engineering, College of Science and College of Architecture and Design.

The ILE sequence will briefly be described. The first course, Introduction to Illumination Engineering and its laboratory are described in more detail later. Various methods of instruction including lectures, self work, industrial visits and guest lectures, as well as the accompanying laboratory work are discussed. Feedback from the students was very positive.

KEY WORDS: Illumination, Illumination Engineering Minor, Lighting, Lighting Minor, Lighting Design, Cal Poly University, Pomona, Energy Savings, Illumination Laboratory

\section{INTRODUCTION}

The need to create a steady flow of new professionals with knowledge of lighting has become clear as need to conserve e lighting energy became a concern of the Federal Government and the State of California with the passage of the National Energy Policy Act of 1992 and Title 24 of the California Code of Regulations. With an estimated 35 percent of the energy consumption in the United States due to lighting, there are many numerous opportunities to save energy and thus resources. Moreover, lighting has until the recent past been taken for granted as a matter of aesthetics and not an energy consumption issue; lighting in both industrial, commercial and residential applications is inefficient and wasteful leaving a lot of room for significantly improved energy efficiency. Putting in place new government regulations without availing the public of the proper education and expertise has long been recognized to be an ineffective way to go.

ALPAC (Advanced Lighting Professional Advisory Committee), an advisory committee to the California Energy Commission, recognized such needs for educating professionals in the field and launched a program to develop educational programs in California community colleges and in a university. Cal Poly Pomona, with its capable Engineering, Science and Architectural Colleges and its well-known "hands on" approach was selected to oversee the program.

Initial funding of $\$ 150,000$ was made available for two and one half years. Six community colleges were chosen to participate in the program. With help and guidance by Cal Poly and ALPAC, representatives from the community colleges developed a lighting curriculum consisting of six courses. A curriculum consists of the following courses:

$\begin{array}{ll}\text { - } & \text { Introduction to Lighting } \\ \text { - } & \text { Lighting Design I } \\ \text { - } & \text { Lighting Design II } \\ \text { - } & \text { Building System Applications } \\ \text { - } & \text { Applied Lighting Technology } \\ & \text { Advanced Lighting Design }\end{array}$


To date two groups of students have completed the six course sequence at Citrus and Consumnes Community Colleges. Details of the curricula and the course outlines will be available later this year on the Cal Poly Home Page on Internet. Also, the course materials are available for anyone interested in lighting education.

The College of Engineering program for a minor in Illumination Engineering (ILE) consists of four new courses and their associated laboratories and two additional existing courses (24 units). Pre-requisites include math, physics and chemistry courses taken by all engineering and science students as a pre-requisites for their own individual majors. Hence, the ILE minor is directed toward these students because it uses material covered in several engineering disciplines essential to ILE. This permits the course Introduction to Illumination Engineering which covers a wide variety of illumination related topics in detail to begin at an advanced level. Details of this course will be introduced below, and methods of instruction for multidiscipline engineering students discussed.

The four new courses that were developed for the ILE minor include:

Table I: Illumination Engineering Course Offerings

\begin{tabular}{|c|c|c|}
\hline Course Title & $\begin{array}{c}\text { Course/Lab } \\
\text { Units }\end{array}$ & Offered \\
\hline 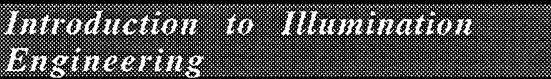 & (4.) & 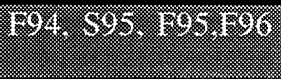 \\
\hline 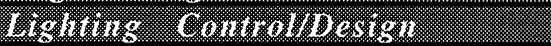 & 4.1) & 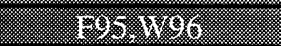 \\
\hline 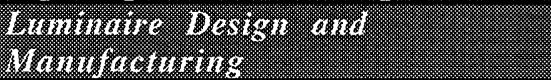 & 4.13 & 1798,596 \\
\hline 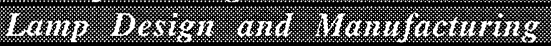 & 41 & 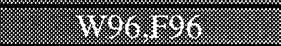 \\
\hline
\end{tabular}

The Introduction to ILE course is the primary subject of this paper.

\section{INTRODUCTION TO ILLUMINATION ENGINEERING: COURSE DEVELOPMENT}

With financial support from the DOE and the California Energy Commission, the Electrical and Computer Engineering (ECE) Department in the College of Engineering at Cal Poly Pomona embarked on the development of course outlines and materials for the above courses. The first to be completely developed and offered with its laboratory was the Introduction course. To facilitate development and ensure success, the course was modeled after similar courses in other institutions where a graduate degree in ILE or an Illumination minor to Architecture students are offered. In fact, in schools around the world where Illumination/Lighting are taught, the responsibility for the curriculum lies almost always within the School of Architecture and not with the School of Engineering. One school where ILE has been taught as part of the electrical Engineering curriculum is University of New Hampshire. There, Dr. Joseph Murdoch has developed a fine and demanding ILE program. The latest edition of his book $(1)$ is the primary textbook for the course at Cal Poly with other books $(2,3,4$, 5) used as references. Since Cal Poly Pomona's philosophy has always been that students learn-by-doing, a three hour weekly laboratory session reinforces the course material. Material for the course and the laboratory also includes many handouts, demonstrations and visits to lighting centers such as Southern California Edison's CTAC facility and fixture manufacturers.

\section{INTRODUCTION TO ILLUMINATION ENGINEERING: COURSE CONTENTS}

The requirements and pre-requisites for the Introduction to ILE course is depicted in Table II.

Table II: Course Requirements and Pre-requisites

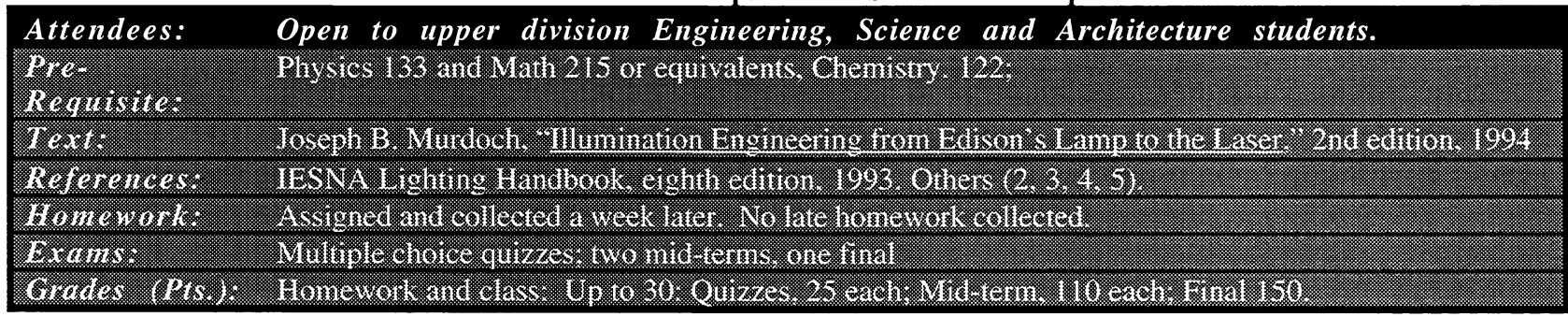


The outline for the Introduction to Illumination Engineering is depicted in Table III. The quarter system at Cal Poly dictates a ten week term. Hence, the material depicted in Table III covers rather extensive ground and demands a lot of the students.

Table III: Course Outline

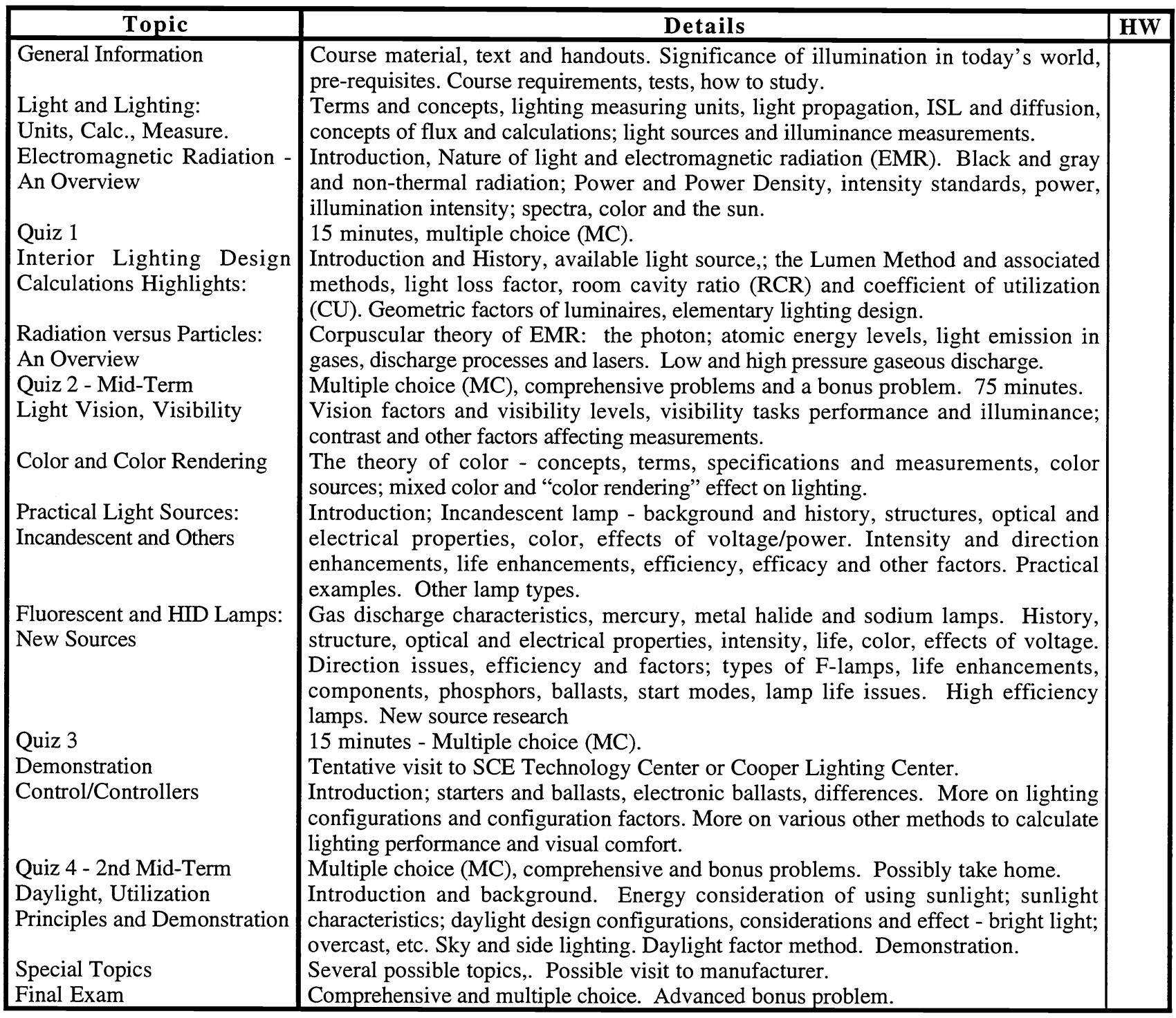

To reinforce the class studies, notes on specific subjects are handed out, homework assigned every week, several experts in their fields, (e.g., color, vision, etc.) are invited as guest lecturers and their handouts and presentations are part of the course material. Students are responsible for all material.

\section{INTRODUCTION TO ILLUMINATION ENGINEERING - LABORATORY}

The one unit-three hour/week laboratory that supplements the lecture includes a variety of fundamental experiments in light, light sources, indoor and outdoor field measurements, designs of office and class lighting systems, design-construction-testing of luminaires, etc. A sample outline is shown below in Table IV. 
Table IV: Introduction to Illumination Engineering - Laboratory Outline. ( 8 wks, 1 unit.)

\begin{tabular}{|c|c|}
\hline TO & LS \\
\hline $\begin{array}{l}\text { Introduction } \\
\text { Terminology, Measurements } \\
\text { Elementary Measurements } \\
\text { Field Measurements } \\
\text { Quiz 1 - (tentative) } \\
\text { Field Measurements } \\
\text { Factors Effecting Lamp } \\
\text { Performance } \\
\text { Field Measurements } \\
\text { Summary - CTAC Visit } \\
\text { Design \& Implementation of } \\
\text { Office/Class Lighting to } \\
\text { Specifications } \\
\text { Design, Construction and } \\
\text { Test } \\
\text { Industrial Visit (TBD) } \\
\text { Special Session (TBD) } \\
\text { Quiz 2 }\end{array}$ & $\begin{array}{l}\text { General Introduction: Overview, basic safety guidelines. } \\
\text { Definitions, terms and measurements. Integrating sphere calibrations. } \\
\text { Point source approximations validation; diffused sources; square law verification, properties } \\
\text { of laser light. } \\
\text { Division into teams. Measurements and mapping of lighting sources and lit areas of various } \\
\text { outdoor locations on campus. Analysis and critique. } \\
\text { Multiple choice, } 20 \text { minutes, terms and definitions. } \\
\text { Division into teams. Measurements/mapping of lighting sources and indoor areas of various } \\
\text { location on campus. An analysis and critique assignment. } \\
\text { Absolute and relative measurements of performance of incandescent and fluorescent light } \\
\text { sources with voltage and temperature integrating spheres. } \\
\text { Class summary and critique of the lighting in various parts of the campus mapped in the last } \\
\text { experiment. Suggestions and proposals. Report Introduction to illumination; a visit to } \\
\text { CTAC, SCE's Technology and Development Center. } \\
\text { Design a class lighting system and development of a model. Comparison of model to a few } \\
\text { classrooms or laboratories in the Engineering Building. Summary and critique. } \\
\text { Teams to design a light fixture to specs, construct the fixture, calibrate it, compare to specs } \\
\text { and adjust fixture to meet the specs. Award. } \\
\text { A visit to a lamp/luminaire manufacturer. } \\
\text { General discussion of lighting experiments, results interpretation. } \\
\text { Multiple choice. } 30 \text { minutes. All material related to experiments and interpretation of such. }\end{array}$ \\
\hline
\end{tabular}

As part of the laboratory, students are responsible to process any information collected and present it in an easily understandable report with charts, graphs, summary and conclusions. Laboratory reports are an important part of the grades.

\section{FACILITIES AND SUPPORT SERVICE}

Classes are held in regular classrooms. Demonstrations and lab sessions are held in a laboratory and outdoor field measurements are conducted on campus. All of Cal Poly University resources such as stockrooms, machine shop, technicians, video facilities are available to the students. A Photometric laboratory has been designed for use by the lighting program, as well as the Optoelectronics, Biomedical and Laser Programs. Laboratory facilities will include the equipment needed to demonstrate various theories and phenomena. Lecture demonstration equipment such as light boxes, visual/effect boxes are being developed as senior projects by students. Equipment in use includes various photometers, reflectance meters, spectrometer, radiation photometers, integrating sphere, automatic current/voltage/power measuring equipment, computers, a large variety of light sources, and many tools. Students have access to the Instrumentation ,Simulation, and Control Laboratory and can use the equipment and virtual measuring tools available via the use of LABVIEW. A picture of the lab is depicted in Figure I. Student projects consist of building a goniophotometer using LABVIEW, building calibration instruments for light sources, and light boxes. The use of virtual instruments is also part of the laboratory. Planned equipment in the Laboratory also includes a multi-luminaire ceilings with a independent controllers, displays of operating light sources, various stations to conduct different experiments, several integrating spheres, automated computer controlled goniophotometer, a sophisticated data acquisition system, light boxes and much more. It is expected that the laboratory will provide a suitable place to conduct evaluation of and research projects on light sources and luminaires, controllers and optical systems. Typical laboratory workstations are shown in Figure II. With industry support, which has already been offered, the College expects to provide various services to the industry and to the community. 


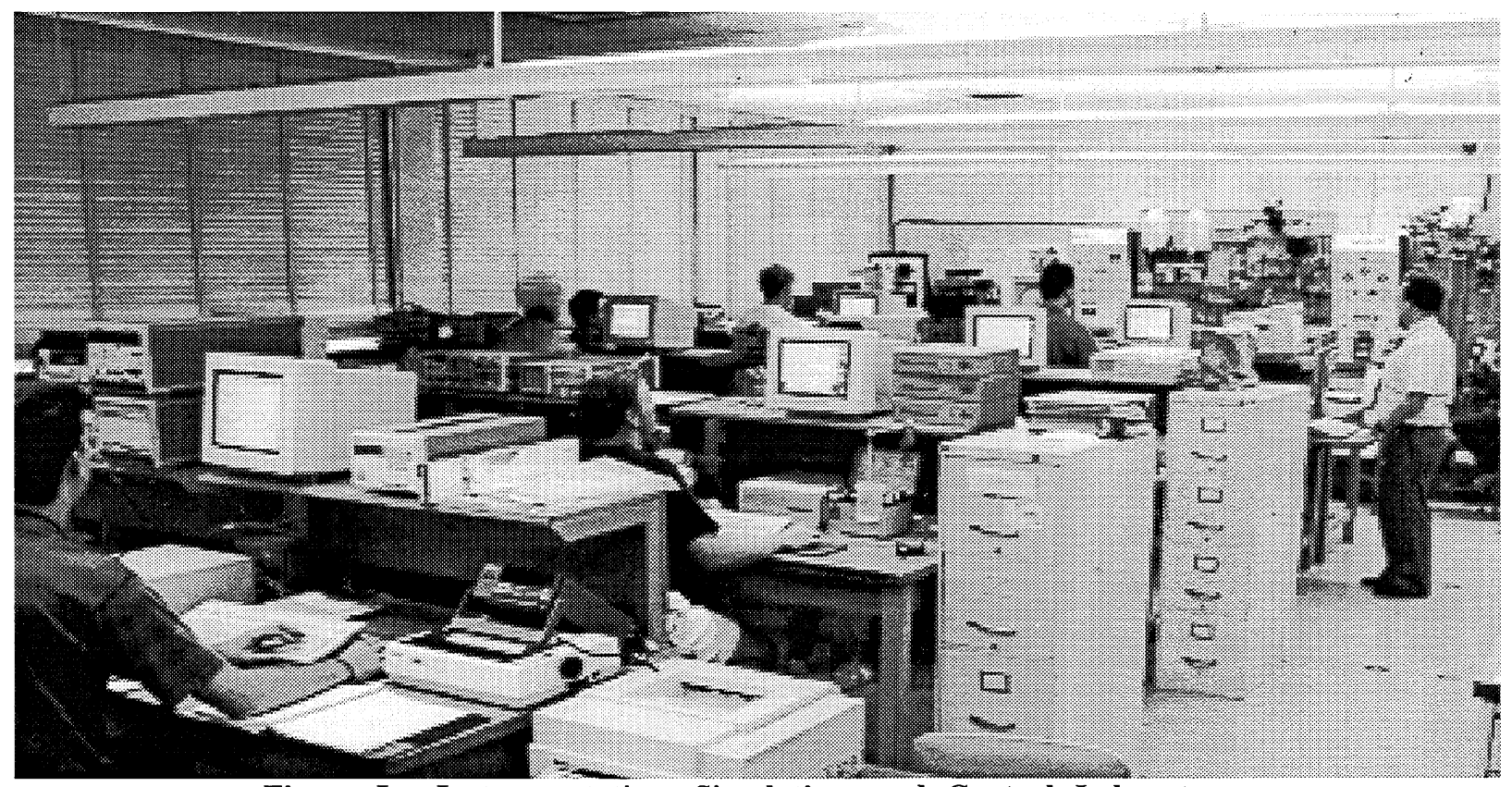

Figure I. Instrumentation, Simulation, and Control Laboratory
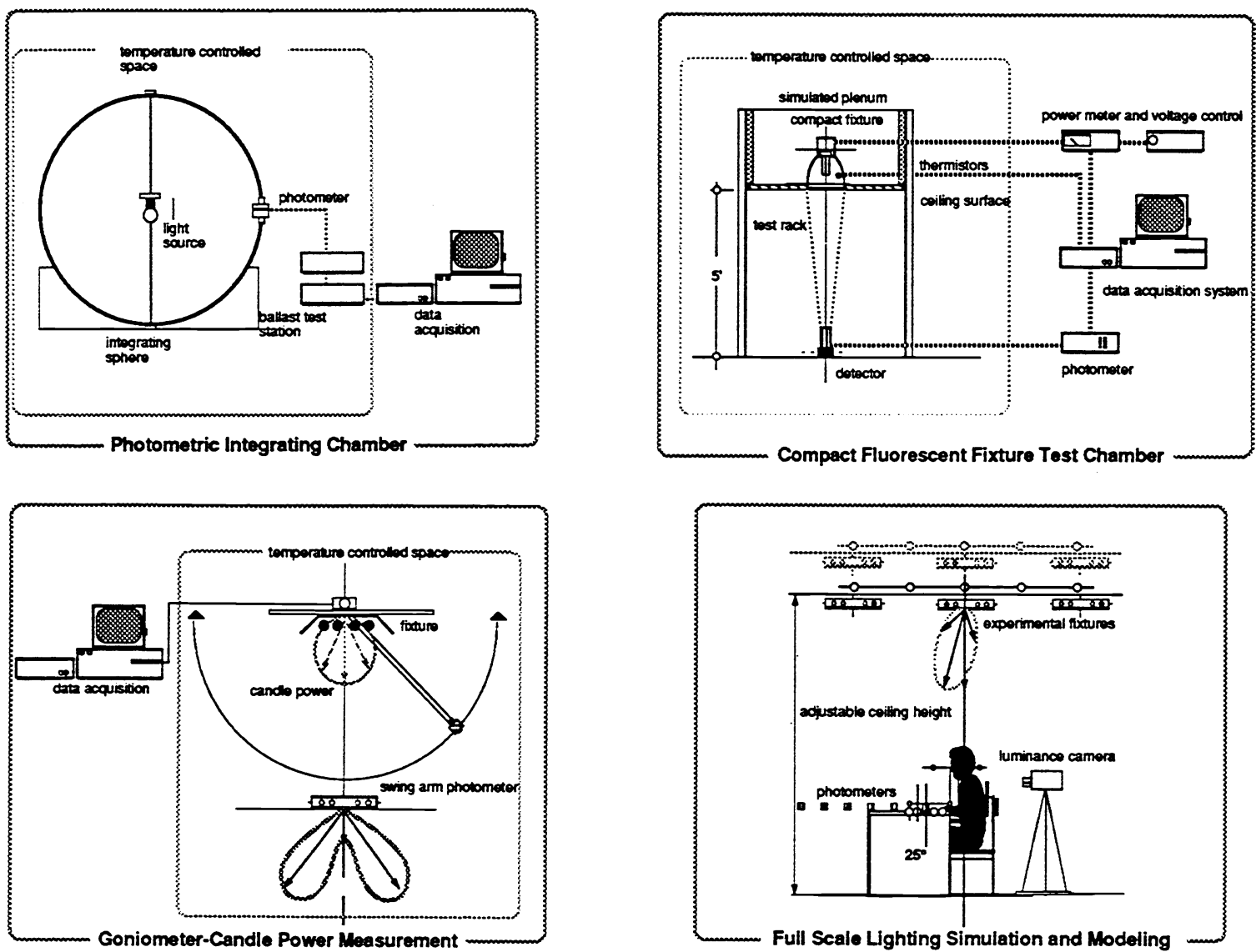

Figure II. Typical Laboratory Workstations Developed by Dr. Rudy Verderber and Dr. Mike Sminovitch of Lawrence Berkeley Laboratories University of California 


\section{INSTRUCTIONAL METHODS - THE MULTI-DISCIPLINED CLASS}

To date, attendees to the Introduction to Illumination Engineering courses have consisted of Electrical Engineering, Engineering Technologists, Electrical Industrial and Material and Mechanical Engineering students. The course is also targeted toward Architectural and Civil Engineering students, various people who are already employed in the lighting industry, people from the utilities and the manufacturers of luminaires and controllers. To accommodate this broad spectrum of students, the Introduction course uses various pedagogical tools. These include:

- A requirement that attendees have the needed previous training (pre-requisites or equivalent education or experience) and mathematics through calculus.

- An engineering textbook with many lighting examples and problems.

- Reference books that throw more light on the subjects. A lighting reference library is available to students.

- Reference material and data books supplied to the University (for distribution to students) by the industry, e.g., GE, Phillips and others.

- Notes prepared by the faculty.

- Video and live demonstrations of various concepts and equipment.

- Guest lectures and demonstration by specialists in fields as color, vision and photometrics.

- Appropriate facilities and photometric equipment.

- Prepared laboratory experiments, demonstrations, photometric measurements, construction and testing projects and indoor and outdoor field measurements.

- Weekly homework assignments and some extra sessions with the class to go over such assignment, with all worked out solutions available to students.

- Opportunity to carry our Senior Projects in Illumination as part of the major.

- Periodic comprehensive quizzes and tests: these include several multiple choice broad scope quizzes, comprehensive class exams and a take-home project.

Visit to industrial manufacturers and to utilities technical centers such as Southern California Edison Technical Center (CTAC).

To accommodate the short (10 weeks) term, all lectures and laboratories were prepared in detail before the class, using a variety of teaching aids: overhead transparencies and slides, Video tapes, Copies of the actual lectures and summaries.

\section{SUMMARY AND CONCLUSIONS - A POSTSCRIPT}

A course sequence for an Illumination Engineering minor has been developed and is being taught at Cal Poly Pomona. The first course in the sequence, Introduction to Illumination Engineering, and its lab companion have been described in this paper. The courses, geared at present to engineering, science and architectural students, are going to be further developed so as to serve practicing engineers, architectural technicians, specifiers and purchasing agents and utilities and industrial people who seek to have training in illumination. The need for a growing number of people knowledgeable in lighting comes about because of the need to conserve energy and the increasing role of government energy policy in achieving that goal. Part of that policy was responsible for the funding provided to empower Cal Poly Pomona to launch an appropriate lighting program in California's Community College system and an Illumination Engineering minor in the College of Engineering. Both objectives have been met: Lighting Program graduates of two of the community colleges are coming out this year and the first courses/labs in the ILE minor have been taught. A schedule of classes for the coming two years is in place. Feedback from students has been very positive, as it has been from Industry.

An integrated photometric/illumination lab has been designed and is projected to be constructed and equipped in 1995/96. Altogether, the illumination programs at the Community Colleges and at Cal Poly have made strong progress and are very promising. 


\section{ACKNOWLEDGMENT}

The authors wish to thank those who have contributed to the success of the program at California State Polytechnic University, Pomona, California. Some of the major contributors are Dr. Joseph Murdoch of the University of New Hampshire, Dr. Dave De Laura of University of Colorado, Dr. Clarence Waters of Kansas State University, Dr. Craig Bernecker of Pennsylvania State University, Dr. Rudy Verderber and Dr. Michael Siminovitch of Lawrence Berkeley

Laboratory University of California. We appreciate the support received from Drs. Glenn Healey and Don Hoffman of University of California at Irvine and the continuous support of the program by Dr. Ed Hohmann, Dean of College Engineering and Interim Vice President for Academic Affairs for California State Polytechnic University, Pomona.

\section{REFERENCES AND BIBLIOGRAPHY}

1) Joseph B. Murdoch, "Illumination Engineering From Edison's Lamp to the Laser, second edition, Visions Comm., 1994

2) Jack L. Lindsey, “Applied Illumination Engineering” The Fairmont Press Inc., 1991

3) Ronald N. Helms, M. Clay Belcher, "Lighting for Energy Efficient Luminous Environments", Prentice Hall, 1991

4) Marc Schiler, "Simplified Design of Building Lighting" John Wiley and Sons, 1992

5) IES Lighting Handbook, 8th edition, 1993 